\title{
Long-term Oncologic Outcomes of Laparoscopic Resection for Colorectal Cancer
}

\author{
Seung-Yong Jeong \\ Department of Surgery, Seoul National University College of Medicine, Seoul, Korea
}

See Article on Page 64-70

Several large randomized trials comparing laparoscopic versus open resection for colon cancer have demonstrated that the laparoscopic-assisted colectomy can be an acceptable alternative to an open colectomy for colon cancer [1-4]. These trials suggested similar oncologic outcomes (local recurrence and overall survival) for laparoscopic-assisted and open colectomies. In addition, laparoscopic-assisted resection may be associated with a shorter hospital stay with no difference in intra-, peri- and postoperative complications. To date, however, the laparoscopic resection for rectal cancer has not gained level-1 evidence in surgical practice. A subset analysis of the UK Medical Research Council (MRC) trial, Conventional versus Laparoscopic-Assisted Surgery in Colorectal Cancer (CLASICC), reported a 34\% conversion rate with $59 \%$ morbidity during the first 30 days after laparoscopic surgery for rectal cancer. Laparoscopic procedures for rectal cancer are regarded as technically demanding because a total mesorectal excision (TME) and autonomic nerve preservation are prerequisites for functional and oncological safety.

In Korea, the laparoscopic resection for colorectal cancer was introduced by some pioneering surgeons in the early 1990's and currently, it is growing in popularity. In this issue, Lee et al. reported the long term oncologic outcomes for 303 patients who underwent a laparoscopic resection for colorectal cancer (colon, 115; rectum, 188). The recurrence rate was $2.2 \%$ for colon cancer and $4.4 \%$ for rectal cancer. The five-year overall and disease-free survival rates were $86.1 \%$ and $89.8 \%$ for colon cancer and $68.6 \%$ and $74.5 \%$ for rectal cancer, respectively. The authors concluded that laparoscopic surgery for colorec-

Correspondence to: Seung-Yong Jeong, M.D.

Department of Surgery, Seoul National University Hospital, Yeongeon-dong, Jongno-gu, Seoul 110-744, Korea

Tel: +82-2-2072-0152, Fax: +82-2-766-3975

E-mail: syjeong@snu.ac.kr

(c) 2011 The Korean Society of Coloproctology

This is an open-access article distributed under the terms of the Creative Commons Attribution NonCommercial License (http://creativecommons.org/licenses/by-nc/3.0) which permits unrestricted noncommercial use, distribution, and reproduction in any medium, provided the original work is properly cited. tal cancer is a good alternative method to open surgery, with tolerable oncologic long-term results. The oncologic outcomes in their study are comparable to those of a conventional open resection for colorectal cancer, even when compared to those of high-volume, leading cancer centers. The results of this study can stimulate a surge in applications of laparoscopy in the field of colorectal cancer surgery. However, as with open surgery, the safety and the benefits of laparoscopy still lie with the surgeons, who must develop competency along a personal learning curve that assures proper patient selection, technical performance, and a low conversion rate. In addition, surgeons who have already overcome the learning curve and attained proficiency should endeavor to develop and establish systematic teaching programs for young surgeons, including surgical residents and fellows.

\section{REFERENCES}

1. Lacy AM, Garcia-Valdecasas JC, Delgado S, Castells A, Taura P, Pique JM, et al. Laparoscopy-assisted colectomy versus open colectomy for treatment of non-metastatic colon cancer: a randomised trial. Lancet 2002;359:2224-9.

2. Clinical Outcomes of Surgical Therapy Study Group. A comparison of laparoscopically assisted and open colectomy for colon cancer. N Engl J Med 2004;350:2050-9.

3. Jayne DG, Guillou PJ, Thorpe H, Quirke P, Copeland J, Smith AM, et al. Randomized trial of laparoscopic-assisted resection of colorectal carcinoma: 3-year results of the UK MRC CLASICC Trial Group. J Clin Oncol 2007;25:3061-8.

4. Colon Cancer Laparoscopic or Open Resection Study Group, Buunen M, Veldkamp R, Hop WC, Kuhry E, Jeekel J, et al. Survival after laparoscopic surgery versus open surgery for colon cancer: long-term outcome of a randomised clinical trial. Lancet Oncol 2009; 10:44-52. 